\title{
A strategic approach to police interactions with people with a mental illness
}

\author{
Terry G. Coleman, ${ }^{*}$ and Dorothy Cotton ${ }^{\dagger}$
}

\begin{abstract}
Since the birth of modern policing in the early 1800s, police agencies have interacted with persons with mental health problems (P/MHP) whether in crisis, as victims, or in a support role. Given the nature of policing, this is unlikely to change. What has changed is how police handle these situations. This paper identifies and explains the two phases of the evolution, to date, of police responses and the now necessary third phase. It is time for police agencies to apply a focussed corporate approach to this important social issue and to establish a mental health strategy (third generation) in order to clearly take a strategic approach in concert with relevant community agencies to improve outcomes for P/MHP who come into contact with police personnel. While many standalone programs have been primarily reactive, this paper makes the case that a strategic approach enables the design and implementation of multiple programs congruent with the mental health strategy that are proactive as well as reactive, all with the aim of improving the outcomes for persons with mental illness and mental health problems.
\end{abstract}

Key Words Co-response team, proactive, reactive, Mental Health Commission of Canada, mental health strategy, strategic leadership/management, TEMPO

Journal of CSWB. 2016 Aug;1(2):7-11

www.journalcswb.ca

\section{INTRODUCTION}

In 1988, police in Toronto were called to the residence of Lester Donaldson, a man who suffered from paranoid schizophrenia. Mr. Donaldson had been apprehended by police on several previous occasions pursuant to the Mental Health Act and charged over time with several minor crimes. On this occasion, Mr. Donaldson produced a knife, confronted police and was subsequently shot and killed. His death and the subsequent recommendations of the Coroner's Inquest (Chief Coroner on Ontario, 1994) heralded the beginning of an era of legislative review and program development centred on the creation of cooperative ventures between Canadian police and mental health agencies.

Fast forward to 2013, when then Chief of Police William Blair of the Toronto Police Service (TPS) requested that the Honourable Mr. Justice Frank Iacobucci, a retired Justice of the Supreme Court of Canada, undertake an independent review of the use of lethal force by the TPS, with a particular focus on encounters between police and "people in crisis", following several incidents in which people with apparent mental illnesses had died in interactions with police (Iacobucci, 2014).

There is no doubt that people in crisis-also described in the literature as people with mental illnesses, people with mental health problems or emotionally disturbed people ${ }^{a}$ - continue to have frequent interactions with police (Boyce, et al., 2015). The reasons are complex. While the situation has been commonly blamed on the de-institutionalization movement of the 20th century, there are additional reasons. Improved medications and other therapies have made it possible for many people who would formerly have required custodial care to live independently. There have also been shifts in social attitudes which have influenced legislation making it (appropriately) more difficult to detain people in hospital against their will, thus depriving them of basic liberties (Gray, et al., 2008). Furthermore, there are often insufficient mental health services to meet the needs of people who need them, and even when services are available, wait lists might be long, and access awkward. Finally, insufficient services, combined with the stigma associated with mental illness, often make people reluctant or unable to take advantage of existing services.

The result has been that the local police, as the de facto $24 / 7$ social agency in many communities, have often found themselves as gatekeepers to the mental health system, and

This paper uses $\mathrm{P} / \mathrm{MHP}$ (people with mental health problems) which includes people who might be in crisis, have a psychiatric disorder or appear to be experiencing difficulties in perception, cognition, or mood. 
have been described as "the front line extension of a mental health system" (Chief Coroner of Ontario, 1994). In the absence of alternatives, police accepted this role. Consequently, contrary to the suggestion by some that the situation has not changed since the death of Lester Donaldson, there has been significant change and evolution of police interventions, including the development of education and specialized response programs. However, questions remain. Is additional education, training, and programming sufficient? Do these initiatives address the core problem or has this approach been repeatedly addressing only symptoms of social issues? The evidence would suggest that the number of recorded interactions between police and $\mathrm{P} / \mathrm{MHP}$ continues to increase. According to Boyce et al. (2015), in 2012 there were approximately one million police contacts in Canada with persons with mental illness and/or with substance abuse issues. The purpose of this paper is to discuss progress to date, and consider the necessary future direction in order to effectively address issues related to police interactions with $\mathrm{P} / \mathrm{MHP}$.

\section{THE EVOLUTION: FIRST GENERATION}

Police interventions over time can be conceptualized as falling into three, somewhat overlapping, generations. The first generation can be largely characterized by a need for education and training. The prevailing belief was that situations that ended badly did so because of a lack of knowledge and skills on the part of police officers. Indeed, the single most common recommendation by coroners' inquests and similar inquiries related to deaths of $\mathrm{P} / \mathrm{MHP}$ in interactions with police has been that there is a need for increased education and training related to mental health problems (Coleman \& Cotton, 2005; Police Complaints Authority, 2003). Findings such as these have helped to ensure that such education is now the norm (Coleman \& Cotton, 2015). For instance, in recognition of the frequency and importance of callsfor-service involving people with mental health problems, most police colleges/academies in North America provide at least nominal training and education in this area. Many police agencies also provide additional education and training to some, or all, personnel including call takers and dispatchers.

One of the most comprehensive discussions of the essential components of an effective education and training regime are contained in a report commissioned by the Mental Health Commission of Canada (Coleman \& Cotton, 2014). This TEMPO learning framework (Training and Education about Mental Illness for Police Organizations) articulates learning objectives and key principles that help to ensure that education and training are comprehensive, while also ensuring that the framework is applicable to a wide range of police agencies and jurisdictional needs. In addition to providing a firm basis of knowledge for police personnel, the framework embraces a human rights/anti-stigma philosophy, provides for a range of education appropriate to diverse police audiences, emphasizes a systems approach to police/mental health liaison activities, and addresses issues related to the design, delivery, and implementation of police/mental health education and training.

\section{THE EVOLUTION: SECOND GENERATION}

However, as stated above, education and training, while essential, are insufficient. The second generation of police initiatives (which developed in parallel rather than subsequent to education initiatives), has included police-based response programs aimed at focussing specific police resources on the issue. For instance, as early as the late 1970s (in Canada) and mid-1980s (in the US), specialized police-based P/MHP response programs were beginning to emerge. By far the most well-known in the US is the police-based Crisis Intervention Team (CIT) program, which originated in Memphis, Tennessee in 1988. However, it is important to note that this is not the only model and not necessarily the most appropriate program for every jurisdiction.

In Canada, there are a variety of joint mobile-response programs ${ }^{b}$ (also called co-response programs or teams); in fact, this appears to be the predominant Canadian response model. Reuland (2012), as well as Cordner (2006), noted that selection of an appropriate program for police encounters with $\mathrm{P} / \mathrm{MHP}$ will, to some extent, be determined by the nature of the challenges confronting the local jurisdiction. As Reuland pointed out, the right question to ask is not which program is best, but rather which one is most appropriate and meets the requirements of the respective jurisdiction. Reuland suggested relevant community characteristics are:

the nature and style of leadership in the police agency; required procedures for medical clearance and admission to mental health facilities in the region;

- the nature and availability of mental health resources in general;

- the specific legislation at all levels that might determine the options available to police; and

- the demography and geography of the specific jurisdiction.

Many major Canadian cities employ some kind of joint co-response model (e.g., Montreal, Halifax, Toronto, Hamilton, Edmonton, Vancouver), as well some smaller jurisdictions (e.g., Chatham-Kent in Ontario). Reviews suggest there are many benefits to these co-response programs (e.g., see Shapiro et al. (2015) and Allen Consulting Group (2012)). However, while popular, CIT and co-response teams are only examples of types of programs developed in recent years. Many police agencies have developed programs unique to the needs of their jurisdictions. What all these models have in common, however, is that they tend to be standalone programs and are often not well integrated into the broader services of police agencies. The result is they are not part of a strategic approach.

While increased knowledge and education in combination with add-on and focussed programs have appeared to improve police responses to $\mathrm{P} / \mathrm{MHP}$ over time, there is also no doubt that substantial unaddressed problems remain.

\footnotetext{
b Usually staffed by police and a mental health nurse or a mental health social worker.
} 
These include:

The tendency for educational initiatives to address only a subgroup of diagnostic groups or problem types. Interestingly, there is no common language or term used to describe the large number of vulnerable people whose difficulties involve not only mental illness but also cognitive impairment and developmental disabilities, including brain injury, autism, dementia, and so forth. Some programs only target a single age group (e.g., they might either focus on or exclude children and youth, or seniors). While this might reflect the organization of social services and health services, it is not consistent with the practice of policing.

- Police agencies have often not taken a problem-solving approach to calls they receive regarding $\mathrm{P} / \mathrm{MHP}$. Instead, many of the response programs tend to be reactive and repeatedly respond to symptoms of social issues rather than working effectively with other agencies to address underlying health and social problems.

- Educational initiatives are often isolated from other police learning; in particular, there is rarely integration with use of force training. Some educational initiatives can also be overly focussed on knowledge acquisition, as opposed to skill acquisition.

- Both education and standalone response programs often fail to reflect interactions with $\mathrm{P} / \mathrm{MHP}$ in a wide variety of contexts. Furthermore, such interactions sometimes co-occur in environments in which there might be other focussed police programs or initiatives-such as homelessness, situations involving use of force (e.g., SWAT ${ }^{\mathrm{C}}$ or $E T^{d}$ responses), domestic violence, elder abuse, victim services, initiatives aimed at special populations such as youth, GLBTQ+ populations, or specific community groups defined by either location or ethnic composition. A focus on police-based programs has been on 'crisis intervention', yet the majority of police interactions with P/MHP do not involve a crisis (Brink et al., 2011; Belleville Police Service, 2007). In particular, there has been little in the way of developed responses to frequent users of police services - the minority of $\mathrm{P} / \mathrm{MHP}$ who make numerous demands on police and community services. The identification and measurement of outcomes has been problematic. Many programs have lacked a clear statement, or even an understanding, of goals. This makes rigorous evaluation and the determination of a successful outcome difficult. For example, is the goal to reduce injury? Reduce hospital wait times? Decrease the number of arrests? Improve relations with the mental health community? Increase referrals to other community agencies? Or decrease the likelihood of reinvolvement with police?

\section{THE EVOLUTION: THIRD GENERATION}

These limitations point to the need for a broader strategic approach to interactions with $\mathrm{P} / \mathrm{MHP}$ - the third generation; that is, an approach based on a police agency's mental health

Special Weapons and Tactics.

Emergency Response Team. strategy which, in turn, is congruent with the police agency's organizational (corporate) strategy.

At the core of a strategic approach is the establishment of a clear organizational (corporate) strategy that is wellcommunicated both internally and externally. Such a corporate strategy is usually composed of several components including the agency's mission, vision, and corporate values (Thompson, 2003; Jones, 2004). This is what guides strategic leadership and management, and also enables the community to hold their police agency accountable for results.

Congruent with the respective organizational (corporate) strategy, functional strategies are necessary to shape and guide the police agency's decisions and actions (tactics) (Beamish \& Woodcock, 1999). In much the same way as progressive police organizations, for example, establish functional strategies such as an Organized Crime Strategy or a Domestic Violence Strategy, a Mental Health Strategy can make a clear declaration about the organization's position and intent, including the commitment of resources, concerning all aspects of interactions with $\mathrm{P} / \mathrm{MHP}$, ranging from proactive as well as reactive. So why is a mental health strategy-a strategic approach-necessary, and what should it include?

A well-crafted mental health strategy, established in consultation and collaboration with the community and mental health stakeholders, makes the position and goal(s) of a police organization and its activities regarding interactions with $\mathrm{P} / \mathrm{MHP}$ clear both externally to the public, including health and mental health agencies, as well as within the organization to all personnel. That is, such a strategy is 1) an important means of communication, 2) a means of establishing and achieving objectives, and 3) a way of maintaining direction and commitment to achieve an integrated comprehensive approach and fulfill the agency's mission.

The goals and objectives of the mental health strategy are achieved by means of the programs and tactics linked to the strategy. That is, programs are no longer orphans but are designed and delivered to satisfy goals of the mental health strategy and, thus, the police agency's strategic goals. Examples of such programs/tactics are the various co-response teams, CIT programs or other programs that fit the strategy. Arguably, if a program/tactic is not congruent with the mental health strategy, it is not the right program. Similarly, if the activities of a program/tactic are not meeting strategic goals, then it is likely the program is improperly implemented, requires a redesign or requires replacement. Furthermore, the establishment of strategic outcome goals reflected in related programs enable the critical rigorous evaluations that, in large part, have been missing from a solely program or tactical approach.

Without being prescriptive or limiting the scope of a mental health strategy regarding interactions with $\mathrm{P} / \mathrm{MHP}$, the strategy should serve a variety of purposes including:

enabling an improved focus on root causes of police interacting with $\mathrm{P} / \mathrm{MHP}$ rather than continually addressing the symptoms of the problem;

- ensuring that the intended nature of police interactions with $\mathrm{P} / \mathrm{MHP}$ reflects sensitivity to local issues including demographic and cultural factors;

ensuring that police agencies establish productive relationships and work effectively with the mental health 
system, as well as with other relevant government and non-government agencies;

- signaling to the external and internal constituencies the desired culture of the police agency;

enabling a focus on the desired outcomes of proactive and reactive police activities related to interactions with $\mathrm{P} / \mathrm{MHP}$;

be structured, along with its related proactive and reactive programs, to enable measurement, research, and continuous improvement;

- facilitating a change of police organizational attitudes and culture with regard to mental health problems; and, most importantly,

- maximizing, for all parties, the likelihood of positive outcomes of police interactions with $\mathrm{P} / \mathrm{MHP}$.

\section{A strategic approach should also embrace:}

the importance of leadership and the role of police leaders;

the creation of a stigma-free environment;

the importance of problem solving;

the education and knowledge that serve as preparation for all interactions with $\mathrm{P} / \mathrm{MHP}$;

- the importance of including $\mathrm{P} / \mathrm{MHP}$ in the planning and delivery of programs and services;

- the need for a variety of response programs, addressing not only crises but the wide variety of other situations in which police interact with $\mathrm{P} / \mathrm{MHP}$; such programs should meet the need of a variety of age groups and population;

- the development and maintenance of community linkages reflecting a systems approach;

a focus on the initial contact with $\mathrm{P} / \mathrm{MHP}$ which includes call takers and dispatch personnel;

- the development of readily available and accessible mental health consultation within the community as needed; the need for understandings and agreements with the health system including local hospital emergency departments;

- relevant data-driven and data-informed program development and evaluation; and

appropriate employee selection and job assignment (Cotton \& Coleman, 2015).

Currently, few police agencies have established a mental health strategy to guide their responses to police interactions with $\mathrm{P} / \mathrm{MHP}$. One example is the Australian strategic document, Policing People Who Appear To Be Mentally Ill, which is comprehensive and clear (Policing People, 2012). Another recent well-constructed and articulated mental health strategy is that of the Ontario Provincial Police, Canada (Ontario Provincial Police, 2015).

Although few Canadian police agencies have such strategies under development, some, even though as of yet without a mental health strategy per se, have a broad range of services with goals that address many of the concerns that would be reflected in a mental health strategy. For example, Hamilton Police, Ontario, in conjunction with St. Joseph's Healthcare Centre, have been long-time leaders in their work with $\mathrm{P} / \mathrm{MHP}$. While they are probably best known for their co-response team COAST, ${ }^{\mathrm{e}}$ Hamilton has additional programs that include:

a high visibility foot/bike patrol team in the downtown core where about $80 \%$ of their mental health encounters occur, supported by a Social Navigator ${ }^{\mathrm{f}}$ who proactively acts to prevent crises by linking individuals to services and community partners;

a mobile response team that does not include police; several co-response teams which include a mental health worker and a police officer, including teams focussed on services to adults, children and family, and seniors; a suicide prevention helpline;

crisis intervention education and training which has been completed by approximately half of first-responder police officers; all police personnel will complete a program specific to suicide presentation;

a co-response Mobile Crisis Rapid Response Team (MCRRT) in which a mental health worker and a police officer are first responders to situations involving $\mathrm{P} /$ MHP;g and

- an MOU in partnership with St. Joseph's, has reduced hospital wait times from an average of 2.5 hours to 70 minutes for police officers and under an hour for the MCRRT.

One of the striking features about the comprehensive approach that Hamilton Police and the COAST programs have developed is the extent to which they are driven by local community needs, informed data collection, outcome measures, and evaluation.

\section{CONCLUSIONS}

As recently as the 1990s, many police agencies in Canada did not provide formal education and training of police officers to prepare them for contacts with $\mathrm{P} / \mathrm{MHP}$ and many did not have formal organizational response models. However, there has since been significant change to the extent that education and training are the norm, and many different co-response models utilized.

Notwithstanding this progress, it is time for police agencies to apply a focussed corporate approach to this important social issue, and to establish a mental health strategy in concert with relevant community agencies to improve outcomes for $\mathrm{P} / \mathrm{MHP}$ who come into contact with police personnel. While many standalone programs have been primarily reactive, a strategic approach-the third generation-makes it possible to design and implement multiple programs congruent with the mental health strategy that are proactive as well as reactive, all with the aim of improving the outcomes for persons with mental illness and mental health problems.

\section{CONFLICT OF INTEREST DISCLOSURES}

The authors confirm that there are no conflicts of interest.

\footnotetext{
Crisis Outreach and Support Team.

This is a relatively new but promising initiative.

The MCRRT results are promising.
} 


\section{AUTHOR AFFILIATIONS}

*Department of Justice Studies, University of Regina, Regina, SK 'Department of Psychology, Queens University, Kingston, ON, Canada.

\section{REFERENCES}

Allen Consulting Group. (2012). Police, Ambulance and Clinical Early Response (PACER) evaluation: Final report. Melbourne, AU: Department of Health, State of Victoria.

Beamish, P.W., \& Woodcock, C.P. (1999). Strategic management: text, readings and cases, 5th edition. Toronto, ON: McGraw-Hill Ryerson.

Belleville Police Service. (2007). Police interactions with emotionally disturbed/ mentally ill people: a comprehensive analysis and review. Belleville, Ontario.

Boyce, J., Rotenberg, C., \& Karam, M. (2015). Mental health and contact with police in Canada, 2012. Ottawa, ON: Juristat, Canadian Center for Justice Statistics, Statistics Canada. Catalogue no. 85-002X. Retrieved March 17, 2016, from http://www.statcan.gc.ca/pub/85002-x/2015001/article/14176-eng.htm?WT.mc_id=twt

Brink, J., Livingston, J.D., Desmarais, S., Greaves, C., et al. (2011). A Study of How People with Mental Illness Perceive and Interact with the Police. Retrieved March 17, 2016, from Mental Health Commission of Canada website: http://ww.mentalhealthcommission.ca

Chief Coroner of Ontario. (1994). Explanation for Donaldson verdict (File 14679). Toronto, ON: Ministry of Solicitor General.

Coleman, T., \& Cotton, D. (2005). A study of fatal interactions between Canadian police and mentally ill. Paper presented at the 2005 International Association of Law and Mental Health Annual Conference, Paris, France.

Coleman, T.G., \& Cotton, D.H. (2014). TEMPO: Police interactions: A report towards improving interactions between police and people living with mental health problems. Ottawa, ON: Mental Health Commission of Canada. Retrieved March 5, 2016, from http://www.mentalhealthcommission.ca/English/document/36596/tempo-police-interactions-reporttowards-improving-interactions-between-police-and-pe

Cordner, G. (2006). People with mental illness. Problem oriented guides for Police. Problem-specific guides series no. 40. Washington, DC: US
Department of Justice, Office of Community Oriented Policing Services Retrieved March 1, 2016, from http://www.popcenter.org/problems/ mental_illness/print/

Cotton, D., \& Coleman, T. (2015). Contemporary policing guidelines for working with the mental health system 2015. Ottawa, ON: Mental Health Commission of Canada. Retrieved 18 March, 2016 from http:/ www. mentalhealthcommission.ca/English/document/78366/contemporarypolicing-guidelines-working-mental-health-system-2015

Gray, J.E., Shone, M.A., \& Liddle, P.F. (2008). Canadian mental health law and policy, 2nd edition. Markham, ON: LexisNexis.

lacobucci, F. (2014). Police encounters with people in crisis. Toronto, ON Toronto Police Service. Retrieved 17 March, 2016, from http://www. torontopolice.on.ca/publications/files/reports/police_encounters_with_ people_in_crisis_2014.pdf

Jones, G.R. (2004). Organizational theory, design and change: Text and cases, 4th edition. Upper Saddle River, NJ: Pearson Education, Inc.

Ontario Provincial Police. Ontario provincial police mental health strategy: Our people, our communities. (2015). Ontario, ON: OPP. Retrieved 15 March, 2016, from http://www.opp.ca/ecms/files/289727191.pdf

Police Complaints Authority. (2003). Review of shootings by police in England and Wales from 1998 to 2001. London, UK: Police Complaints Authority.

Policing people who appear to be mentally ill. (2012). Victoria, AU: Victoria Government Printer. Retrieved March 17, 2016, from http://www. parliament.vic.gov.au/file_uploads/Policing_people_who_appear_to_ be_mentally_pył8YbmN.pdf

Reuland, M. (2012). Tailoring the police response to people with mental illness to community characteristics in the USA. In D. Chappell (Ed.), Police responses to people with illnesses: Global challenges (pp. 27-41). London, UK: Routledge.

Shapiro, G.K., Cusi, A., Kirst, M., O'Campo, P., Nakhost, A., \& Sterngiopolous, V. (2015). Co-responding police-mental health programs: a review. Adm Policy Ment Health, 42:6-6-620. doi:10:1007/s10488-014 0594-9

Thompson, J.L. (2003). Strategic management: awareness and change, 3rd edition. London, UK: Thomson Learning. 